\title{
Effect of Frusemide on Pulmonary Blood Volume
}

\author{
M. L. BHATIA,* M.D., D.M. ; INDER SINGH,† F.R.C.P.ED., F.R.C.P.GLASG., F.A.M.S.; S. C. MANCHANDA, $\ddagger$ M.D. \\ P. K. KHANNA, $\dagger$ M.D., D.M. ; SUJOY B. ROY,§ F.R.C.P.ED., F.A.M.S.
}

British Medical fournal, 1969, 2, 551-552

\begin{abstract}
Summary : Intracardiac frusemide given to ceven $\checkmark$ patients recovering from high-altitude pulmonary oedema caused a significant reduction in the pulmonary blood volume before the onset of diuresis. This supports the suggestion that the mobilization of fluid from the pulmonary circuit is responsible for the relief of symptoms in some patients with pulmonary oedema even when a diuresis does not occur.
\end{abstract}

\section{Introduction}

Biagi and Bapat (1967) reported the dramatic effect of frusemide (Lasix) in relieving the symptoms in a 65-year-old patient critically ill with acute pulmonary oedema many hours before the onset of diuresis. They suggested that frusemide first caused fluid to be removed from the pulmonary circulation and then produced a diuresis. To test this hypothesis the effect of intravenous frusemide on the pulmonary blood volume was studied in seven patients recovering from high-altitude pulmonary oedema. These patients were chosen because previous studies (Roy et al., 1965b, 1965c) had shown that their pulmonary blood volume generally remained increased for 3 to 24 weeks after they had been evacuated to the plains and their symptoms relieved.

\section{Subjects and Methods}

Studies were made on seven men aged 24 to 29 years, three to eight weeks after recovery from pulmonary oedema. Before cardiac catheterization they were all asymptomatic and had normal physical findings, electrocardiograms, and chest radiographs.

The patients were studied in the fasting state without sedation. Right heart catheterization was performed by positioning a No. 7 cardiac catheter in the pulmonary artery just beyond the valve. The left atrium was entered by the percutaneous transseptal Brockenbrough method (Brockenbrough and Braunwald, 1960) as practised in our laboratory (Roy et al., 1963). The right femoral artery was cannulated to obtain arterial blood pressure and dye curves. Consecutive dyedilution curves were obtained direct on a Polyviso channel through a continuous recording densitometer (Colson) by injecting $2.5 \mathrm{mg}$. of indocyanine green dye into the main pulmonary artery and then into the left atrium. The difference in the mean transit times of the two resulting curves was taken as the pulmonary transit time. The cardiac output was measured from the dilution curves by the formula of Hamilton et al. (1932). The volume of blood between the pulmonary artery and the left atrium was calculated by multiplying the pulmonary mean transit time by the average cardiac output ; this represented the pulmonary blood volume. Similarly, the volume of blood between the pulmonary and femoral arteries was obtained by multiplying the pulmonary-artery-to-femoralartery mean transit time by the average cardiac output; this represented the central blood volume. Details of the technique

\footnotetext{
* Associate Professor of Cardiology, All India Institute of Medical Sciences, New Delhi-16.

† Directorate General, Armed Forces Medical Services, New Delhi-1.

$\ddagger$ Research Fellow, All India Institute of Medical Sciences, New Delhi-16.

5 Professor of Cardiology, All India Institute of Medical Sciences, New Delhi-16.
}

have already been reported (Roy et al., 1965a). The total blood volume was determined by the Evans blue dye method (Gibson and Evans, 1937).

The intracardiac and femoral artery pressures were recorded through P23AA strain gauge manometers on a four-channel single-gun photographic system. The baseline for all pressure measurements was taken as being half the chest thickness at the second costal cartilage when the patient was lying supine (Roy et al., 1957). After obtaining the control data, $40 \mathrm{mg}$. of frusemide was injected into the pulmonary artery. Pressures in the pulmonary artery, left atrium, and femoral artery were intermittently recorded for the next 15 minutes, and then second set of cardiac output, pulmonary blood volume, and pressure measurements was obtained (see Table).

\section{Results}

The pulmonary blood volume, compared with our normal values (range 145 to 310 , average $210 \mathrm{ml}$./sq. m.), was found to be significantly increased in two men (Cases 5 and 6) and was high normal in three others (Cases 1, 3, and 7). The central blood volume was within the normal range. Intracardiac frusemide caused an average fall in the pulmonary blood volume by $23 \%$ and in the cardiac output by $33 \%$, but a decrease in central blood volume-in only six subjects-by an average of $11 \%$. The total blood volume, which was measured in only two men (Cases 6 and 7), had decreased significantly in both. Furthermore, the heart rate and the femoral and pulmonary artery pressures did not change after giving frusemide; but, whereas the filling pressures and work index of both ventricles decreased, the pulmonary and systemic vascular resistances increased.

\section{Discussion}

The finding that intracardiac frusemide decreased the pulmonary blood volume within 15 minutes of administration and before the onset of diuresis in the seven patients reported above supports the hypothesis of Biagi and Bapat (1967). Similarly it also explains in part the haemodynamic basis for the clinical improvement which also sometimes occurs. Nevertheless, the percentage reduction of the pulmonary blood volume in the present study could not be related to the changes seen either in the central blood volume or in the cardiac output. As similar data on the acute response of the pulmonary blood volume to intravenous frusemide are not available comparisons cannot be made. In a previous sturdy with intravenous morphine, however, the $26 \%$ decrease in the pulmonary blood volume value could also not be related to the $19 \%$ decrease in the central blood volume or to the $15 \%$ decrease in cardiac output (Roy et al., 1965c). In addition, Samet and Bernstein (1968), using intravenous ethacrynic acid in 27 subjects, reported that the pulmonary blood volume decreased by $12 \%$ and the cardiac output by $20 \%$.

The events following the circulatory response to intravenous frusemide were probably initiated by a reduction in the total plasma volume, a decrease in the venous return, a fall in the ventricular filling pressures, and a decrease in cardiac output. The role of the total blood volume in the present study, however, cannot be critically appraised, as it was estimated in only two cases (both of which showed considerable decrease), bex 
Effect of Frusemide on Pulmonary Blood Volume and Circulatory Dynamics in Seven Subjects Convalescing from High-altitude Pulmonary Oedema

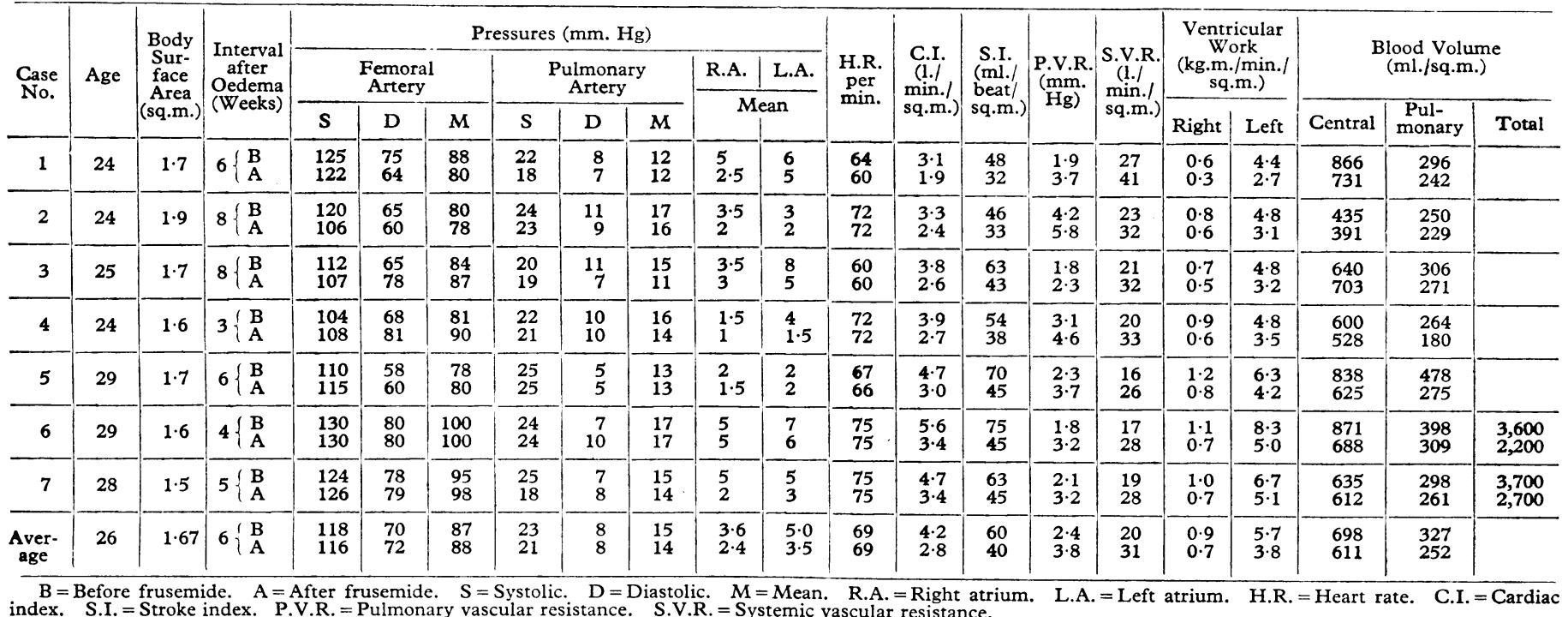

$B=$ Before frusemide. $A=$ After frusemide. $S=$ Systolic. $D=$ Diastolic. $M=$ Mean. R.A. $=$ Right atrium
index. S.I. = Stroke index. P.V.R. = Pulmonary vascular resistance. S.V.R. = Systemic vascular resistance.

in another similar study in progress at present the average fall in the total blood volume value in eight patients was $20 \%$. Furthermore, the total blood volume of five patients with congestive cardiac failure fell by $21 \%$ following the administration of $100 \mathrm{mg}$. of intravenous frusemide (Davidov, Kakaviatos, and Finnerty, 1967). In the present study it may therefore be surmised that the total blood volume might also have fallen in the other five cases. If reduction in total blood volume initiates circulatory changes the role of the pulmonary blood volume in the chain of events has to be ascertained. The discrepancy between the reduction in the levels in the pulmonary and central blood volumes by frusemide supports our previous observation that the response of the pulmonary blood volume to high-altitude hypoxia was independent of the central blood volume (Roy et al., 1967). This may represent a form of homoeostasis between the pulmonary and the extrapulmonary blood volumes.

We wish to acknowledge our indebtedness to the Director-General, Armed Forces Medical Service; the Director-General, Indian Council of Medical Research; and the Director of the All India
Institute of Medical Sciences for their ungrudging support and encouragement for the present study.

\section{REFERENCES}

Biagi, R. W., and Bapat, B. N. (1967). Lancet, 1, 849.

Brockenbrough, E. C., and Braunwald, E. (1960). American fournal of Cardiology, 6, 1062.

Davidov, M., Kakaviatos, N., and Finnerty, F. A., jun. (1967). fournal of the American Medical Association, 200, 824.

Gibson, J. G., and Evans, W. A., jun. (1937). Fournal of Clinical Investigation, 16, 301.

Hamilton, W. F., Moore, J. W., Kinsman, J. M., and Spurling, C. G. (1932). American fournal of Physiology, 99, 534.

Roy, S. B., Gadboys, H. L., and Dow, J. W. (1957). American Heart

Roy, S. B., Bhatia, M. L., and Guleria, J. S. (1963). Indian Heart fournal, 15, 255.

Roy, S. B., Bhardwaj, P., and Bhatia, M. L. (1965a). British Medical Fournal, 2, 1466

Roy, S. B., Bhatia, M. L., Singh, I., and Khanna, P. K. (1965b). In Symposium on Problems of High Altitude, p. 49. Poona, Armed Forces Medical College.

Roy, S. B., Singh, I., Bhatia, M. L., and Khanna, P. K. (1965c). British Heart fournal, 27, 876.

Roy, S. B., Bhatia, M. L., and Gadhoke, S. (1967). American Heart fournal, 74, 192.

Samet, P., and Bernstein, W. H. (1968). American fournal of Medical Sciences, 255, 78.

\section{Preliminary Communications}

\section{Oral Phenylalanine and Tyrosine Tolerance Tests in Parkinsonian Patients}

\section{British Medical fournal, 1969, 2, 552-555}

Summary: Reduction of dopamine concentrations in the brains of patients with Parkinsonism, together with reported clinical improvement after the administration of dihydroxyphenylalanine, has led to the hypothesis that impaired hydroxylation of tyrosine may be associated with the disease. To test this hypothesis oral loading tests with L-phenylalanine and tyrosine were carried out in patients and controls. After phenylalanine lower blood levels of this were found in Parkinsonian patients than in controls, but tyrosine levels were the same. After tyrosine lower levels of this were also found in patients compared with controls. It is suggested that these findings indicate a decreased rate of tyrosine utilization in Parkinson's disease together with intestinal malabsorption; the latter is supported by the finding of abnormal $\mathrm{D}-\mathrm{xy}$ lose tolerance in these patients.

\section{INTRODUCTION}

Increasing evidence supports the belief that abnormal aromatic amino-acids and catechol metabolism may be responsible for the manifestations of Parkinson's disease. Interest has centred chiefly on the role of dihydroxyphenylalanine, which is the precursor of both melanin (decreased in the substantia nigra of patients with Parkinsonism) and dopamine (found in reduced quantities in the substantia nigra and the corpus striatum of 